\title{
M0 Stage Finding
}

National Cancer Institute

\section{Source}

National Cancer Institute. Mo Stage Finding. NCI Thesaurus. Code C48699.

A distant metastasis TNM finding indicating that there is no evidence of distant metastasis. 